\title{
Correcting Misconceptions in Fractions Using Interactive Technological Learning Activities
}

\author{
Mohammad Ahmad Alkhateeb \\ Hashemite University \\ Zarqa, Jordan \\ https://orcid.org/0000-0003-2289-7982
}

\begin{abstract}
This study aimed to diagnose the misconceptions of the fractions subject with the fourth graders and identifying the effect of using interactive activities to correct the misconceptions that the students experience in the fractions subject. The researcher applied the quantitative method and the quasi-experimental design for the one-group pre-test/post-test design. This includes conducting a pre-test that aimed at diagnosing the misconceptions in the fractions. The possibility of correcting misconceptions was tested using interactive technological activities. The study sample consisted of 85 fourth graders in Jordan. The results revealed a pool of misconceptions in the fractions subjects. Two of the most common misconceptions comprised $88.3 \%$ and $80 \%$ of the misconceptions, respectively. The first one was subtracting nonequivalent fractions through subtracting the two numerators by considering this as the result of the final numerator and subtracting the two non-equivalent denominators taking the output as the result of the denominator. The second misconception was adding a fraction to an integer by adding the integer to the numerator of the fraction by considering it as a numerator of the result, and keeping the denominator of the fraction as it is, which represents the denominator of the final result. Furthermore, the results showed an increase in the mean from 4.15 in the pretest to 8.9 in the post-test. This is a strong indicator that the use of the interactive learning activities that were created helped to correct the misconceptions in the learning of fractions.
\end{abstract}

Keywords: ADDIE model; interactive technological activities; misconceptions in fractions

\section{Introduction}

Students, worldwide, suffer from difficulties in fraction learning, because it is one of the difficult subjects the students face throughout their basic and secondary stages (Bailey, Hoard, Nugent \& Geary, 2012; Bruce \& Ross, 2009; Chen, Pan, Sung \& Chang, 2013; Pal, 2014). This is ascribed to that the facts that the students learned about the integers do not apply to the fractions (Lortie-Forgues, Tian \& Siegler, 2015). For example, adding the integers does not apply to adding the 
fractions; multiplication of the fractions does not always lead to a result that is more than the number multiplied by; and, division processes do not produce a result that is less than the number divided by.

According to the National Council of Educational Research and Training (NCERT, 2008), the difficulties in learning the fractions may be due to several reasons. For instance, the students' use of prior knowledge about the integers when they learn the fractions, and the tendency of the schoolbooks and teachers to teach the fractions and operations on them in a manner that has no effect on the student in real life. Therefore, the students feel the need for the fractions in the math lesson only. These and other obstacles hinder their understanding of the fractions concept and the related operations.

The constructivism theory emphasized the importance of the context in teaching, the importance of revealing the prior knowledge of the learner, and the active interaction between the learning and the teaching content. In this concern, the learner organizes what he learned in cognitive structures that consist of units of interrelated ideas called the conceptual structures. These structures represent valuable mental tools stored in the memory, which could be retrieved and made use of (Emma, Geller; Son \& Stigler, 2018).

According to this theory, the interaction between the prior knowledge of the learner and the new ideas is termed "adaptation", which includes two processes: assimilation and accommodation. The learner carries out the assimilation process by integrating the new knowledge with prior knowledge that exists in his conceptual structure. On the other hand, the accommodation process includes acquiring information that is new and different from the learner's conceptual structure. This requires amending the nature of the student's structures to deal with the new information (Lazića, Abramovichb, Mrđaa \& Romanoc, 2017).

Posner, Strike, Hewson and Gertzog (1983) indicated, in their theory on the conceptual change, that if the student can solve the problems he faces in the light of the conceptual framework, he has will not feel the need for changing this framework, even if this framework does not solve specific problems successfully. At this point, the learner carries out simple changes on the concepts in his conceptual structure and performs the assimilation process without the need to perform the accommodation process.

Learning depends on linking from the prior knowledge the learner owns, which may help (or hinder) the understanding process. It could consist of incorrect prior knowledge called misconceptions, which cause an inability to understand the new concepts. This could be due to many reasons, such as the learner's inability to link what is already present to what is new, misinterpreting the new concepts to match the prior knowledge; or due to the lack of prior knowledge about the concept. In these cases, the learner will resort to sticking to his previous conceptualizations in the light of his conceptual framework (Namkung, Fuchs \& Koziol, 2018).

The conceptual change begins with the assumption that students, in specific occasions, build the alternative misconceptions about the phenomena based on the lived experience, and that these concepts stand firmly against the striking contrast with the accepted scientific theories that explain these phenomena (Liljedahl, 2011). For example, students deal with the regular fractions as if they 
were integers when they add a fraction to another. They add the two numerators of the fractions and take the addition output as the final result of the new numerator. Also, they add the two denominators and take the addition output as the final result of the new denominator (Chen \& Wang, 2016).

Posner, Strike, Hewson, and Gertzog (1982) see that the student should be quite satisfied with the new concepts he learns, to create an intellectual (cognitive) "conflict" between the current concepts that include the misconceptions and the new concepts. The misconceptions are firmly change-resistant because they are not independent of the cognitive structure of the learners. The main objective lies in creating an intellectual (cognitive) conflict to make the learner un-contented with concepts he currently holds. Therefore, he may accept new concepts that are reasonable, brighter, and more productive in finding solutions to the problems he faces.

Amid the search for effective strategies to remedy such misconceptions, the analysis, design, development, implementation, and evaluation (ADDIE) model appeared. This model provides the necessary steps to design effective technological programs, which may help in establishing a learner-centered approach instead of the teacher-centered approach (Cheung \& Slavin, 2013; Stoyle \& Morris, 2017). The approach depends on the constructivism theory principles, through designing technological activities that act on assisting the learner to build meanings within his/her cognitive structure, and through acquiring experiences that enable him/her to link the new information to the prior knowledge to form the correct concept with him/her. Consequently, interactive technological activities become more applicable and meaningful (Reinhold, Hoch, Werner, Richter-Gebert \& Reiss, 2020; Ross \& Catherine \& Bruce, 2009).

ADDIE model includes successive steps where each step feeds the one next to it. During the analysis stage, the learning outputs and current knowledge the learner possesses are defined. The gaps between the learning outputs and the students' current knowledge are also defined. Finally, the misconceptions are detected to enable the learner to achieve the educational goals and correct understanding. Thereafter, the design, development, application, and evaluations are performed after defining the goals and placing them in a clear manner (Pepin, Choppin, Ruthven \& Sinclair, 2017; Wang \& Hsu, 2009).

In this regard, Yilmaz, Özdemi, and Yasar, (2018) conducted a study aimed at identifying the misconceptions in the fractions of fourth-graders and amending these conceptions through digital stories. The study was conducted on 25 students in Turkey, which showed that the teaching applications designed by digital stories eliminated the errors and misconceptions in the fractions with a vast majority of the students. Most of the students realized the entire definitions of the fractions and were able to perform the mathematical operations on them. The study further showed that most of these students expressed positive views about the use of the digital stories in the lessons, and found that these stories are enjoyable, educational, and constructive.

Ross, Catherine, and Bruce (2009) developed educational programs consisting of a set of activities that dealt with several concepts in fractions, such as representations of the simple fractions and equivalent fractions, comparison of the 
fractions, and expressing the unreal fractions as a fractional number. The activities provided an interactive environment for the students that included a pool of pictures that link the fractions with daily life, such as the use of the pizza and cake pictures to represent the fractions. They also included successive steps of animations. The study found that using electronic activities contributed to the improvement of the students' achievement. The students indicated, during the interview, the researchers conducted, that the activities provided them an interactive learning environment, which enabled them to have control over the speed of their learning and progress in the activities, through using the arrows to move forward and backward and to the main menu, which contains a list of all the names of the activities.

Many studies tackled the issue of the students' misconceptions in the fractions. Students are still suffering from difficulty in learning the fractions and the different mathematical operations on them. For instance, studies of Alkhateeb (2019); Aksoy and Yazlik (2017); Duzenli-Gokalp and Sharma (2010); Hoch, Reinhold, Werner, Richter-Gebert and Reiss (2018); Reinhold, Hoch, Werner, Richter-Gebert and Reiss (2020); Schumacher and Malone (2017); and Trivena, Ningsih and Jupri (2017).

Accordingly, the significance of this study is highlighted as an aspired benefit in providing a remedial strategy to the misconceptions in the fraction subject with the students. The significance also lies in the scarcity of the studies that integrate the conceptual change theory with the electronic activities in correcting the misconceptions in the fractions. The results further contribute to curricula development and shed light on the misconceptions of the students during the learning process. In this regard, the researcher hopes to adopt the interactive technological activities method, as it provides a systematic solution to the students' misconceptions. It could also benefit stakeholders who are involved in developing the math curriculum, who can also add methods and strategies specialized in correcting the misconceptions in the math curricula.

Based on the foregoing, the study aims to achieve two main objectives. First, diagnosing the misconceptions of the fractions subject with the fourth graders; and second, identifying the effect of using interactive technological activities to correct the misconceptions that the students experience in the fractions subject.

Therefore, the study seeks to answer the following questions:

1. What are the misconceptions the fourth graders hold about the fractions subject?

2. What are the effects of using interactive technological activities in correcting the misconceptions of the fourth graders in the fractions subject?

\section{Methodology}

The researcher applied the quantitative method and the quasi-experimental design for the one-group pre-test/post-test design. This includes conducting a pre-test for the one group that aims at diagnosing the misconceptions among the students in the fraction's topic. After that, the possibility of correcting these misconceptions is tested using interactive technological activities, which were constructed in the light of the constructivist theory and Posner Model to change 
the concepts. Then, the same test is repeated in the post-measurement after using the interactive technological activities in teaching the fractions topic, to identify their effects in correcting these misconceptions.

\section{Study Population}

The study consisted of a randomly chosen sample of 85 fourth graders in Zarqa (Jordan) governorate in the academic year 2019-2020, who are taught the Jordanian curriculum, which is in line with NTCM (2000) standards. The Jordanian ministry of education adopts the math books issued by Collins in the United Kingdom (https://collins.co.uk). Students in 3rd-5th grades continue refining their understanding of the computational operations on the fractions and developing computation algorithms using the fractions. Students study the fractions topic in four units in the fourth grade. Also, they are introduced to the primary concepts of fractions in the first, second, and third grades.

Three weeks after the students completed the study of the fraction's topic, the diagnostic pre-test was conducted. No revision was done before the diagnostic pre-test, and students were not informed beforehand that they will undertake the exam. The students worked individually and were not allowed to consult the teacher (in this case, the researcher), or their classmates during the exam.

The researcher obtained the necessary approvals of the concerned parties to conduct the study, with a commitment of the researcher that the data collected will be solely for the purposes of the research, not to be used for any personal purposes or leased to any other party. The participants have informed the details and goals of the study, and the researcher respected the right of the participants to withdraw.

\section{Study Instruments}

\section{1) Diagnostic test}

The test consisted of ten questions that measure ten errors, which could be present with the fourth graders in the fractions subject, which were defined as per their existence in the educational literature. The most frequent errors of the students were chosen (Alkhateeb, 2019; Allen, 2007; Aksoy \& Yazlik, 2017; Bruce \& Ross, 2009; Chang, 2013; Cramer, Wyberg, \& Leavitt, 2008; Ghani, \&, Maat, 2018; Schumacher \& Malone, 2017; Siegler, Fazio, Bailey \& Zhou, 2013; Trivena, Ningsih \& Jupri, 2017). The questions varied throughout the regular fractions, comparison, and the addition and subtraction operations on them. Each question was given one score for the correct answering and zero for the wrong. The questions were presented in a way that shows the errors through the students' answers. For instance, when the students were asked: find the result of the subtraction in the following $\frac{3}{6}-\frac{1}{3}=-$ and write the result in the rectangle: If the answer was $\frac{2}{3^{\prime}}$ we know that the student has the misconception, as he subtracted two unequivalent fractions by subtracting the two numerators and putting the output as the numerator of the subtraction process. Then he subtracted the two denominators putting the output as a denominator of the result.

The test was presented to 6 reviewers to show their views on the clarity degree of the test question, and whether any of them is to be rephrased. In the light of their 
comments, specific questions were amended. The researcher applied the testretest procedures and realized the test reliability. The test was applied to an exploratory sample and was reapplied two weeks later, where the resulting Pearson Correlation Coefficient was 0.87 .

\section{2) Interactive technological activities}

Ten interactive technological activities were designed, which aim to treat the ten misconceptions already mentioned in the fraction's topic. The activities were designed in the light of the two-model frameworks, namely the general model to design teaching (ADDIE Model), and Posner Model for conceptual change. The activities were designed within the intellectual (cognitive) conflict strategy by working within the visualization that a contradiction must be created in the student and his misconceptions must be destabilized, be replaced by the correct concepts. As for the general model for teaching design, the activities were designed within the following stages:

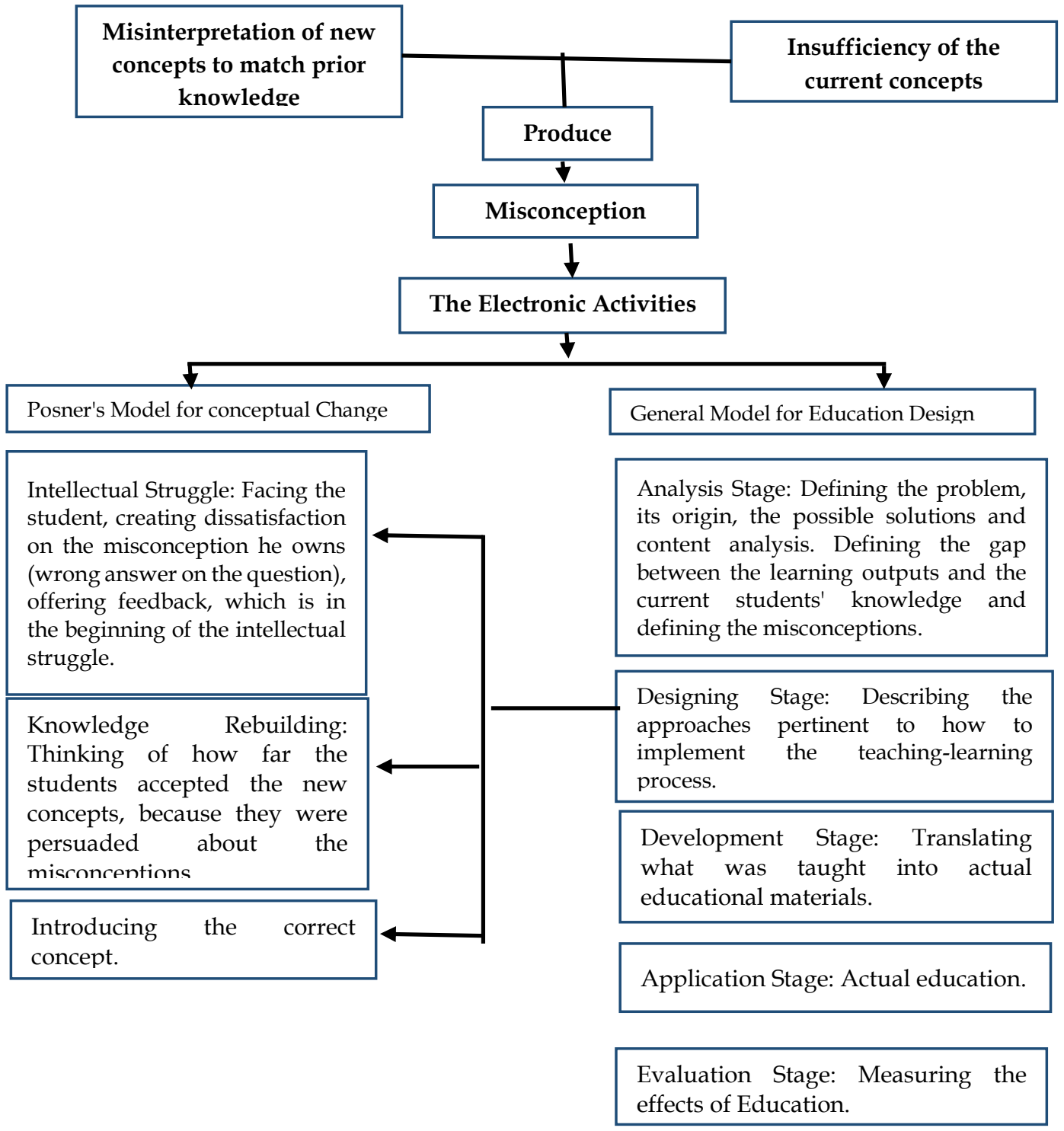

Figure 1: General Model of the Interactive Technological Activities Design 
The validity of the technological activities was verified by presenting them to the reviewers, whose remarks and comments about the nature of the activities, their contents, and the design mechanism were taken into account. Then, the activities were applied to an exploratory sample to find out how convenient the activities are for the students, how easy they are, and how to navigate through the activity's screens. The activities were given to the same exploratory sample two weeks later, and the two experiments were compared to know how close the students' performance in using them was.

\section{Data Gathering Procedures:}

Step 1: Applying the pre-test on the pupils of a school in Zarqa City, to identify the percentage of errors in the fractions topic before the use of technological activities.

Step 2: The researchers taught the pupils the fractions topic using technological activities over 15 lessons. Here below are examples of specific technological activities in the study:

Comparison of two fractions having the same numerator: in the beginning, the activity consists of a multiple-choice question. The student is asked to compare the fractions $\frac{1}{5}$ and $\frac{1}{2}$ by selecting the signs $(><)$, as shown in Figure 2 . If he answers that $\frac{1}{2}<\frac{1}{5}$, the screen will tell that the answer is incorrect, and then an arrow is shown to him to move to the next.

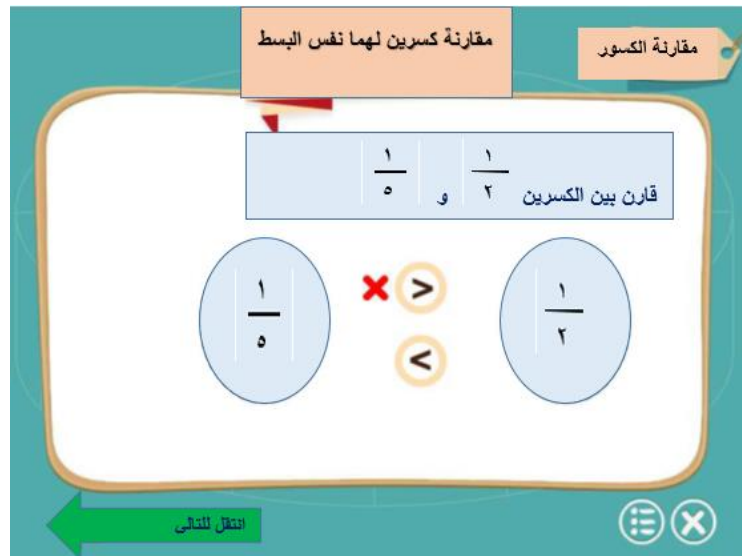

Figure 2: Homepage of the electronic activity

Then the activity displays the incorrect answer of the student in a pictorial manner, as the activity is programmed in a way that enables achieving the theoretical framework of the study. In this regard, Posner, Strike, Hweson and Gertzog (1982) see that for a successful conceptual change process to happen, students must feel dissatisfied about their current concepts, which results in an incorrect answer so that the intellectual conflict will start, as shown in Figure 2. 


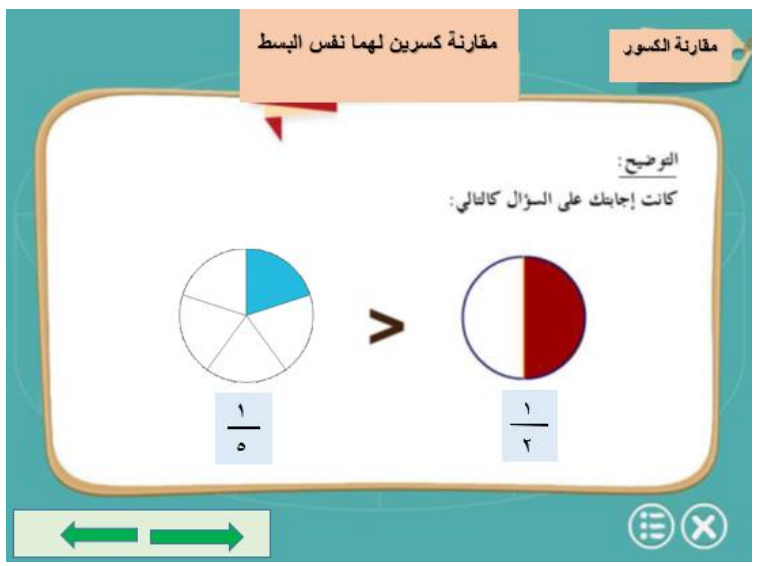

Figure 3: Pictorial comparison that shows the student his incorrect answer to start the intellectual conflict

Figure 3 contains the continuity of the intellectual conflict process, but in a manner closer to the student's reality and his daily life. The student is again asked to compare the fractions $\frac{1}{2}$ and $\frac{1}{5}$, and with a representation of two fractions appearing through using the pizza example.

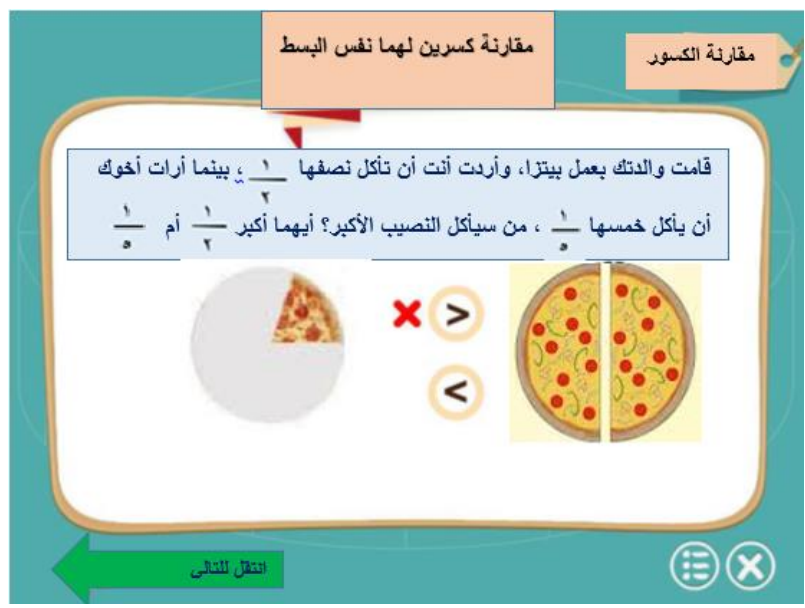

Figure 4: Continuation of the intellectual conflict process

Following the intellectual conflict process and student's destabilization in his answer, the activity moves to the next stage. This stage includes illustrative steps to provide the student's correct knowledge, in which if he sees reasonability and clarity, we can achieve the conceptual change with him. The activity also provides the correct scientific knowledge about how to change the non-equivalent fractions into two equivalent fractions by finding the least common multiple between the two denominators and then making them similar.

Furthermore, the activity includes clarification of the rule the schoolbook deals with, namely: when comparing two fractions with the same numerators, then the fraction with higher denominator is less than the other. It is a quick way that enables the students to answer correctly on comparing two fractions in which numerators are the same. Then, the activity asks the student to compare once more the two fractions $\frac{1}{2}$ and $\frac{1}{5}$ to find out whether the student achieved the objective of 
the activity, or he will repeat the same error. If the student answers correctly, feedback will be presented to him/her, which represents sounds and shapes to encourage him. On the other hand, if the answer was incorrect, the activity will automatically come back to allow the student to start the discovery navigation again until the error is corrected.

Step 3: The post-test was applied after teaching the fractions using the technological activities, which included questions aiming at revealing the extent of the treatment of the error in the fraction's topic, which were found in the pre-test. The researcher changed the order of the questions and the numbers used in the exam items, to ensure that the students did not learn the answers by the heart by repeating the same questions.

\section{Statistical Results}

This study aimed to identify the misconceptions held by students of the fourth grade in the fractions topic. It also aimed to study the effect of using interactive technological activities to correct misconceptions among students, where activities were designed in the light of constructivist theory, Posner's Model, and ADDIE Model.

\section{1) Misconceptions of the fourth graders about fractions}

The misconceptions of the fourth graders on fractions were evaluated and identified through a diagnostic pre-test. The results showed a difference in the percentage of errors the students hold, which were as per the following details. The highest percentage $(88.2 \%)$ was for Misconception Ten: subtracting nonequivalent fractions through subtracting the two numerators and subtracting the two denominators, such as $\frac{3}{8}-\frac{2}{5}=\frac{1}{3}$. Misconception Six comprised $80 \%$, which was about adding a fraction to an integer by adding the integer to the fraction, keeping the denominator of the fraction as is, such as $5+\frac{2}{3}=\frac{7}{3}$. Misconception Eight comprised $74.1 \%$, which was about adding two un-equivalent fractions and adding the two denominators, such as $\frac{5}{7}+\frac{3}{2}=\frac{8}{9}$. Misconception Three accounted for $63.5 \%$, which was about the comparison of two fractions having the same numerator by comparing the two denominators together, such as $\frac{1}{2}<\frac{1}{3}$ because of $3>2$. Misconception Seven amounted $56.5 \%$, which was about adding two fractions with equivalent denominators as well as adding two un-equivalent numerators, such as $\frac{2}{7}+\frac{5}{7}=\frac{7}{14}$. Misconception Nine comprised $52.9 \%$ and was about subtracting two fractions with equivalent denominators and un-equivalent numerators, by subtracting the two numerators and the two denominators, such as $\frac{5}{8}-\frac{2}{8}=\frac{3}{0}$. Misconception Four formed $47.1 \%$ and was about the comparison of two un-equivalent fractions by ignoring the numerator, using the property that "the fraction with higher denominator is the smaller", which applies only on fractions with the same numerator, such as $\frac{1}{3}>\frac{4}{5}$ because of $5>3$. Misconception One amounted to $29.4 \%$ and was about writing a fraction that 
represents the ratio of the shaded part to the un-shaded, not to the whole shape. Misconception Five comprised $27.1 \%$ and was about comparing a fraction with a fractional number by comparing the two fractions while ignoring the integer, such as $1 \frac{1}{5}<\frac{4}{5}$.

Finally, Misconception Two got the lowest percentage (21.2\%) which was about writing a fraction that represents the shaded part of the shape not taking into consideration the unequal portions in the shape. Table 1 shows the misconceptions and their percentages among the students.

Table 1. Students' Misconceptions and their Percentages

\begin{tabular}{|c|c|c|c|}
\hline No. & Misconception & $\begin{array}{l}\text { Students } \\
\text { holding the } \\
\text { misconception }\end{array}$ & $\begin{array}{l}\text { Misconception } \\
\text { Percentage }\end{array}$ \\
\hline 1 & $\begin{array}{l}\text { Writing a fraction representing the ratio of the } \\
\text { shaded part to the un-shaded, not the ratio of } \\
\text { the part to the whole. }\end{array}$ & 25 & $29.4 \%$ \\
\hline 2 & $\begin{array}{l}\text { Writing a fraction that represents the shaded } \\
\text { part of the shape without taking care of } \\
\text { whether the parts are equal in the shape }\end{array}$ & 28 & $21.2 \%$ \\
\hline 3 & $\begin{array}{l}\text { Comparison of two fractions having the same } \\
\text { numerator by comparing the two } \\
\text { denominators together. }\end{array}$ & 54 & $63.5 \%$ \\
\hline 4 & $\begin{array}{l}\text { Comparing two un-equivalent fractions } \\
\text { ignoring the numerator, and using the property } \\
\text { that the fraction with the bigger denominator is } \\
\text { the smaller. }\end{array}$ & 40 & $47.1 \%$ \\
\hline 5 & $\begin{array}{l}\text { Comparing a fraction with a fractional number } \\
\text { by comparing the two fractions while ignoring } \\
\text { the integer. }\end{array}$ & 22 & $27.2 \%$ \\
\hline 6 & $\begin{array}{l}\text { Adding a fraction to an integer by adding the } \\
\text { integer to the numerator of the fraction as a } \\
\text { numerator of the answer, and then taking the } \\
\text { denominator of the fraction as a denominator } \\
\text { of the answer. }\end{array}$ & 68 & $80 \%$ \\
\hline 7 & $\begin{array}{l}\text { Adding two fractions (with un-equivalent } \\
\text { numerators and equivalent denominators) by } \\
\text { adding the two numerators as the numerator of } \\
\text { the answer as well as adding the two } \\
\text { denominators as a denominator of the answer. }\end{array}$ & 48 & $65.5 \%$ \\
\hline 8 & $\begin{array}{l}\text { Adding two un-equivalent fractions by adding } \\
\text { the two numerators as a numerator of the } \\
\text { answer and adding the two denominators as } \\
\text { the denominator of the answer. }\end{array}$ & 63 & $74.1 \%$ \\
\hline 9 & $\begin{array}{l}\text { Subtracting two equivalent fractions by } \\
\text { subtracting the two numerators as the output } \\
\text { of the numerator, as well as subtracting the two } \\
\text { denominators in the same way. }\end{array}$ & 45 & $52.9 \%$ \\
\hline 10 & $\begin{array}{l}\text { Subtracting two un-equivalent fractions by } \\
\text { subtracting the two numerators as the output } \\
\text { of the numerator, as well as subtracting the two } \\
\text { denominators in the same way. }\end{array}$ & 75 & $88.2 \%$ \\
\hline
\end{tabular}




\section{2) Effect of using interactive technological activities in correcting the fourth- graders misconceptions on fractions}

The diagnostic post-test was conducted and the percentage of the correct answers of the ten items of the test on the defined misconceptions was found. The mean of the students' grades was calculated and then compared with their grade mean in the pre-test, to find out the amount of the conceptual change with the students. Table 2 illustrates the misconceptions of the students as we're in the post-test after the use of technological activities, as well as their existence percentage.

Table 2. Students Misconception Percentage after exposure to interactive technological activities as measured by a post-test

\begin{tabular}{|c|c|c|c|}
\hline No. & Misconception & $\begin{array}{l}\text { Students } \\
\text { holding the } \\
\text { misconception }\end{array}$ & $\begin{array}{l}\text { Misconception } \\
\text { Percentage }\end{array}$ \\
\hline 1 & $\begin{array}{l}\text { Writing a fraction representing the ratio of the } \\
\text { shaded part to the un-shaded, not the ratio of } \\
\text { the part to the whole. }\end{array}$ & 0 & 0 \\
\hline 2 & $\begin{array}{l}\text { Writing a fraction that represents the shaded } \\
\text { part of the shape without taking care of } \\
\text { whether the parts are equal in the shape }\end{array}$ & 3 & $3.5 \%$ \\
\hline 3 & $\begin{array}{l}\text { Comparison of two fractions having the same } \\
\text { numerator by comparing the two } \\
\text { denominators together. }\end{array}$ & 5 & $5.9 \%$ \\
\hline 4 & $\begin{array}{l}\text { Comparing two un-equivalent fractions } \\
\text { ignoring the numerator, and using the } \\
\text { property that the fraction with the bigger } \\
\text { denominator is the smaller. }\end{array}$ & 6 & $7.1 \%$ \\
\hline 5 & $\begin{array}{l}\text { Comparing a fraction with a fractional number } \\
\text { by comparing the two fractions while ignoring } \\
\text { the integer. }\end{array}$ & 4 & $4.7 \%$ \\
\hline 6 & $\begin{array}{l}\text { Adding a fraction to an integer by adding the } \\
\text { integer to the numerator of the fraction as a } \\
\text { numerator of the answer, and then taking the } \\
\text { denominator of the fraction as a denominator } \\
\text { of the answer. }\end{array}$ & 11 & $12.9 \%$ \\
\hline 7 & $\begin{array}{l}\text { Adding two fractions (with un-equivalent } \\
\text { numerators and equivalent denominators) by } \\
\text { adding the two numerators as the numerator of } \\
\text { the answer as well as adding the two } \\
\text { denominators as a denominator of the answer }\end{array}$ & 4 & $4.7 \%$ \\
\hline 8 & $\begin{array}{l}\text { Adding two un-equivalent fractions by adding } \\
\text { the two numerators as a numerator of the } \\
\text { answer and adding the two denominators as } \\
\text { the denominator of the answer. }\end{array}$ & 6 & $7.1 \%$ \\
\hline 9 & $\begin{array}{l}\text { Subtracting two equivalent fractions by } \\
\text { subtracting the two numerators as the output } \\
\text { of the numerator, as well as subtracting the two } \\
\text { denominators in the same way. }\end{array}$ & 7 & $8.2 \%$ \\
\hline 10 & $\begin{array}{l}\text { Subtracting two un-equivalent fractions by } \\
\text { subtracting the two numerators as the output } \\
\text { of the numerator, as well as subtracting the two } \\
\text { denominators in the same way. }\end{array}$ & 9 & $10.6 \%$ \\
\hline
\end{tabular}


Table 2 above depicts the change of students' conceptions about fractions after exposing them to the interactive technological activities. Below are the misconceptions of students in the subject matter (Listed in Table 1) on fractions, and the extent of the change that students achieved.

Misconception One: Writing a fraction that represents the ratio of the shaded part to the non-shaded, not to the whole shape. The concept was present with $29.4 \%$ of the students before applying the interactive activities. After applying these activities, all the students managed to answer this question correctly, and the misconception did not appear in the post-test. This is attributed to that the technological activity introduced the concept of the fraction and its divisions (numerator and denominator) in a detailed manner using illustrative pictures. The activity further provided detailed steps on how to write the fraction that represents the shaded part and feedback for the student once he answers. If the answer is incorrect, the activity provides an interactive, illustrative explanation, which contributed in explaining the concept and creating a conceptual change with all the students.

Misconception Two: Writing a fraction that represents the shaded part of the shape without attention to whether the parts inside the shape are equal, which was present with $21.2 \%$ of the students. But, when the interactive activities were applied, it was present with $3.5 \%$ of the students only. Most of the students realized the concept of the integer (1) through the interactive activity, and how to divide it into equal parts so that the total of the parts expresses the denominator of the fraction, and the shaded parts represent the numerator. The researcher noted, through the students' answers, the possibility of falling in the error of considering the non-shaded part in the shape as the denominator of the fraction. In this case, when they are asked to choose the shape in which the shaded part is equal to $\frac{2}{5}$, they tended to choose the pie chart with 3 shaded segments.

Misconception Three: Comparing two fractions that have the same numerator by comparing the two denominators together. This conception was found with $63.5 \%$ of the students, but it dropped to $5.9 \%$ only when the interactive activities were applied. The persistence of the misconception with few students is ascribed to the fact that the conceptual change is sometimes faced with rejection by the students. They adhere to their current misconceptions because they have difficulty in unifying the denominators and finding the least common multiple, which could be linked to the existence of problems among the students in multiplying the numbers.

Misconception Four: Comparing un-equivalent fractions while ignoring the numerator and using the property of the fraction, which is "the fraction with higher denominator is smaller than the other". This misconception was present with $47.1 \%$ of the students and fell to $4.7 \%$ only after the application of the interactive activities. The students used a wrong comparison strategy and compared the two un-equivalent fractions using the strategy for comparing two fractions having the same numerator. They misused the strategy and considered the fraction with a higher denominator smaller than the other. The activity provided a group of pictorial representations and life examples to bring the 
concept close to the students. Then the activity dealt with the strategies to convert the two un-equivalent fractions and then comparing them.

Misconception Five: Comparing a fraction with a fractional number by comparing the two fractions and ignoring the integer. The concept was present with $26.5 \%$ of the students and dropped to $4.5 \%$ only after applying the activity. The students compared the similar thing when comparing the fractions, giving no weight to the integer. This result is in line with that of Ross, Catherine and Bruce (2009), where they indicated that students find difficulties in the fractional numbers concepts because they do not understand the fact that there is a possibility to write an integer beside the fraction. Accordingly, the study emphasizes the necessity to clarify the strategy of converting the fractional number into a fraction to the students as a prior step to compare between the fraction and the fractional number, to avoid the common mistakes the students make.

Misconception Six: Adding a fraction and an integer by adding the integer to the numerator of the fraction as a numerator for the result, then taking the denominator of the fraction as a denominator for the answer. The misconception was held by $80 \%$ of the students, which dropped to only $12.9 \%$ after applying the interactive activity. The conceptual change is attributed to that the activity dealt in the concept of the integer and the fraction that expresses. It is also ascribed to guiding the students to the activity that deals in the first concept that explains the fraction concept and the nature of the numerator and denominator. The activity provided a detailed explanation in an interactional method as well as animations of pizza pieces that represent the integer, then moving with the children to how to add a fraction to an integer.

Misconception Seven: Adding two fractions (that have equivalent denominators) by adding the two numerators and considering the output as the numerator of the answer and the two denominators as the denominator of the answer. The misconception was held by $56.5 \%$ of the students and dropped to $4.7 \%$ after applying the interactive activities. The students applied the strategy for adding the integers and generalizing it to the fraction adding process. The activity contributed to a considerable conceptual change with the students by placing them in an intellectual conflict through real-life examples on how to add two amounts to produce an amount lesser than the two!

Misconception Eight: Adding two un-equivalent fractions by adding the two numerators and considering the output as the numerator of the answer, and adding the two denominators as a denominator of the answer, which was held by $74.1 \%$ of the students, and dropped to $7.1 \%$ after applying the interactive activities. The considerable change rate is ascribed to the reliance of the eighth activity on facing the student with his incorrect answer by the pictorial representation, students asking one the other, and clarifying the fact that when we add two amounts, the resulting amount is bigger than any of the two.

Misconception Nine: Subtracting two equivalent fractions by subtracting the two numerators taking the output as a numerator of the answer and subtracting the two denominators taking the result as a denominator of the answer. The misconception was held by $52.9 \%$ of the students and fell to $8.2 \%$ after applying 
the interactive activities. The students were surprised by the result, as the following example explains the confusion of the student about his answer. He first solved the subtraction process as: $\frac{5}{8}-\frac{3}{8}=\frac{2}{0}$. He soon changed the zero (o) to (1) integer. When he was asked to explain his answer, he said that "it is not allowed to have a zero (0) "beneath" the fraction (denominator), and I replaced it by one (1).

The activity includes clarifying the concept of subtracting two equivalent fractions using the numbers line, which contributed to the assurance of the student's understanding, as mentioned in the study of Siegler, Fazio, Bailey and Zhou (2013). The activity has sequential steps that include dividing the numbers line into equal parts from 0 to 1 , defining the two fractions: the first, then going backward (because the process is subtraction) by the amount of the second fraction to find the result. Students find, at the end of the activity, and enrichment video that contains additional examples on how to subtract two equivalent fractions.

Misconception Ten: Subtracting two un-equivalent fractions by subtracting the two numerators as the output of the numerator and the two denominators as the output of the denominator, which was held by $88.2 \%$ of the students, and went down to $10.6 \%$ only after applying the activity. The activity dealt in activities such as pictorial comparisons to clarify the incorrect answer to the student, then explaining the necessity to uniform two equivalent fractions before carrying out the subtraction process.

The means of the students' scores in the post-test were calculated and compared with those of the pre-test using the Paired Sample Test, to determine whether a conceptual change took place with the students after applying the interactive activities. The results showed an increase in the mean from 4.15 in the pre-test to 8.9 in the post-test, and that $\mathrm{T}=14.33, \mathrm{p}=0.00$, which indicates a difference in favour of the post-test after applying the interactive activities. Consequently, it is an indicator that the use of the interactive activities created a conceptual change with the students as shown in Table (3).

Table 3. Means of the Students Grades in the Pre-test and Post-test as well as T Value

\begin{tabular}{ccccc}
\hline & Pre-test & Post-test & T Vale & Sig \\
\hline Mean & 4.15 & 8.90 & 14.33 & 0.00 \\
S.D & 1.82 & 0.72 & & \\
\hline
\end{tabular}

\section{Discussion}

Through the analysis of the students' answers on the post-test, we found variations in attributing the misconceptions they hold. There were four similar misconceptions in terms of the context: adding two equivalent fractions, adding un-equivalent fractions, subtracting two equivalent fractions, and subtracting two un-equivalent fractions. The students dealt in the questions related to these concepts by adding or subtracting the two numerators making the output as the numerator of the answer, and adding-subtracting the two denominators and making the output as the denominator of the answer. The prevalence of these 
misconceptions was relatively high, such as $\frac{5}{8}-\frac{2}{3}=\frac{3}{5}$. This type of misconception indicates that there are difficulties facing the students in understanding the fractions concepts. The students treat the fractions as if they were integers not paying any attention to the importance of the fraction line. The students further transfer their previous experiences and what they learned in earlier educational stages, such as operations on the integers, to their current stage in fraction learning, which resulted in an overlap in their knowledge that results in the misconceptions.

This result is in line with Allen (2007), who stated that the misconceptions with the students stem from the insufficiency of the prior knowledge. They also stem from misunderstanding the ideas and the conceptual relations between them, which could be obtained through inconvenient ways in a specific context. These results are also in line with the studies of Dhlamini and Kibirige (2014); Siegler, Fazio, Bailey, and Zhou (2013) about students' treatment of the numerator and denominator as totally independent numbers and transferring their previous experiences in adding and subtracting the integers to adding and subtracting the fractions. As a result, this study emphasizes the need to train the teachers to take care of and reveal the students' misconceptions, and the necessary remedial ways. This is quite possible by the teachers' follow-up of the students' answers in the examinations, not to be contented by the "abstract" grades, but they should work to analyze the answers to identify whether the misconceptions exist with the students.

Furthermore, the results showed that the use of the interactive technological activities in the fractions topic is capable to correct the students' misconceptions in the light of compatibility between Posner's Model and ADDIE Model. Therefore, care should be placed on including multiple activities of the misconceptions because misconceptions are change-resistant, as one activity that includes one case is not sufficient to measure the students' conceptual change, as well as using different questions aiming at the misconception.

This result is in line with the study of Reinhold, Hoch, Werner, Richter-Gebert, and Reiss (2020), which showed that it is possible to use an interactive educational environment to teach the fraction concepts. It is also in line with the study of Chen, Pan, Sung and Chang (2013) which showed that conceptual change instructions could correct misconceptions effectively by constructing scenarios that conflict with existing knowledge structures. These results are consistent with the results of a study conducted by Bruce and Ross (2009). The researchers designed five groups of technological activities for the fractions, which contributed to the increase in the students' achievement and reduced their misconceptions.

It is also in line with the study of Yilmaz, Özdemi and Yasar (2018), which showed that the teaching applications designed by digital stories eliminated the mistakes and the misconceptions in the fractions with a vast majority of the students. Most of the students fully realized and understood the definitions of the fractions following the activities designed with digital stories. The study of Stoyle and Morris (2017) is also in line with these results, which showed that the use of the blogs may provide unique support for fractions learning because they provide the students with opportunities to explain, justify, and discuss their thinking. They 
also provide criticism on the logic of others through an interactive educational environment that offers chances to clarify the misunderstandings and misconceptions, which may not be found face-to-face in a traditional educational environment.

\section{Conclusions}

The results of our current study may be an indication that the interactive technological learning activities could lead to an improvement in the understanding of the current misconceptions that students face when learning the fractions topic. As for the content, the focus should not only be on calculating the symbolic fractions, which may seem meaningless for many students, but also on providing convenient educational opportunities to start the required conceptual change. The results show that the use of interactive electronic activities could be used to transfer the different fraction representations to aid the understanding of the concept of fractions. This study is limited to dealing with ten misconceptions only as it takes a lot of time to develop the e-activities which are used to correct these misconceptions.

\section{References}

Aksoy, N., \& Yazlik, D. (2017). Student errors in fractions and possible causes of these errors. Journal of Education and Training Studies, 5(11), 219-233. https://doi.org/10.11114/jets.v5i11.2679

Alkhateeb, M. (2019). Common Errors in Fractions and the Thinking Strategies That Accompany Them. International Journal of Instruction, 12(2), 399-416. https:// doi.org/10.29333/iji.2019.12226a

Allen, D. (2007). Common Misconceptions in Basic Mathematics. Texas A\&M University, $1-$ 12.

Bailey, D., Hoard, M., Nugent, L., \& Geary, D. (2012). Competence with fractions predicts gains in mathematics achievement. Journal of Experimental Child Psychology, 113(3), 447-455. https://doi.org/10.1016/j.jecp.2012.06.004

Bruce, C., \& Ross, J. (2009). Conditions for effective use of interactive on-line learning objects: The case of a fraction's computer-based learning sequence. Electronic Journal of Mathematics and Technology, 3(1), 12-29.

Chen, Y., \& Wang, J. (2016). Analyzing with Posner's conceptual change model and Toulmin's model of argumentative demonstration in senior high school students' mathematics learning. International Journal of Information and Education Technology, 6(6), 457-464. http://dx.doi.org/10.18178/ijiet

Chen, Y., Pan, P., Sung, Y., \& Chang, K. (2013). Correcting misconceptions on electronics: effects of a simulation-based learning environment backed by a conceptual change model. Educational Technology \& Society, 16(2), 212-227.

Cheung, A., \& Slavin, R. (2013). The effectiveness of educational technology applications for enhancing mathematics achievement in K-12 classrooms: A meta-analysis. Educational Research Review, 98-113. https:// doi.org/10.1016/j.edurev.2013.01.001.

Cramer, K., Wyberg, T., \& Leavitt, S. (2008). The role of representations in fraction addition and subtraction. Mathematics Teaching in the middle school, 13(8), 490-496. https:// www.jstor.org/stable/41182601?seq=1 
Dhlamini, Z., \& Kibirige, I. (2014). Grade 9 learners' errors and misconceptions in addition of fractions. Mediterranean Journal of Social Sciences, 5(8), 236-244. http:/ / dx.doi.org/10.5901/mjss.2014.v5n8p236

Duzenli-Gokalp, N., \& Sharma, M. (2010). A study on addition and subtraction of fractions: The use of Pirie and Kieren model and hands-on activities. ProcediaSocial and Behavioural Sciences, 2(2), 5168-5171. https://doi.org/10.1016/j.sbspro.2010.03.840

Emma, H. Geller, E., Son, J., \& Stigler, J. (2018). Conceptual explanations and understanding fraction comparisons, Learning, and Instruction, 52(2017), 122-129. https://doi.org/10.1016/j.learninstruc.2017.05.006

Ghani, N., \& Maat, S. (2018). Misconception of fraction among middle-grade year four pupils at primary school site. Research on Education and Psychology (REP), 2(1), 111 128.

Hoch, S., Reinhold, F., Werner, B., Richter-Gebert, J., \& Reiss, K. (2018). Design and research potential of interactive textbooks: the case of fractions. ZDM Mathematics Education, 50(5), 839-848. https://doi.org/10.1007/s11858-018-0971-z

Lazića, B., Abramovichb, S., Mrđaa, M., \& Romanoc, D. (2017). On the teaching and learning of fractions through a conceptual generalization approach. International Electronic Journal of Mathematics Education, 12(3), 749-767.

Liljedahl, P. (2011). The theory of conceptual change as a theory for changing conceptions. Nordic Studies in Mathematics Education, 16(1-2), 101-124.

Lortie-Forgues, H., Tian, J., \& Siegler, R. (2015). Why is learning fraction and decimal arithmetic so difficult? Developmental Review, 38, 201-221. https://doi.org/10.1016/j.dr.2015.07.008

Namkung, J., Fuchs, L., \& Koziol, N. (2018). Does Initial Learning about the Meaning of Fractions Present Similar Challenges for Students with and without Adequate Whole-Number Skill? Learn Individual Differ, 61, 151-157. https:/ / dx.doi.org/10.1016\%2Fj.lindif.2017.11.018

National Council of Educational Research and Training. (2008). Mathematics Sourcebook on Assessments. NCERT publication.

Pal, M. (2014). Making conceptual knowledge connections to clear misconceptions in fractions in primary classrooms. IOSR Journal of Research $\mathcal{E}$ Method in Education, 4(2), 12-18.

Pepin, B., Choppin, J., Ruthven, K., \& Sinclair, N. (2017). Digital curriculum resources in mathematics education: Foundations for change. ZDM, 49(5), 645-661. https:/ / doi.org/10.1007/s11858-017-0879-z

Posner, G., Strike, K., Hewson, P., \& Gertzog, W. (1982). Accommodation of a scientific conception: Toward a theory of conceptual change. Science Education, 66(2), 211 227. https://doi.org/10.1002/sce.3730660207

Reinhold, F., Hoch, S., Werner, B., Richter-Gebert, J., \& Reiss, K. (2020). Learning fractions with and without educational technology: What matters for high-achieving and low-achieving students? Learning and Instruction, 65, 1-19. https:// doi.org/10.1016/j.learninstruc.2019.101264

Ross, J., Catherine D., \& Bruce, C. (2009) Student achievement effects of technologysupported remediation of understanding of fractions. International Journal of Mathematical Education in Science and Technology, 40(6), 713-727. https:// doi.org/10.1080/00207390902971999 
Schumacher, R., \& Malone, A. (2017). Error patterns with fraction calculations at fourth grade as a function of students' mathematics achievement status. The Elementary School Journal, 118(1), 105-127. https://doi.org/10.1086/692914

Siegler, R., Fazio, L., Bailey, D., \& Zhou, X. (2013). Fractions: the new frontier for theories of numerical development. Trends in cognitive sciences, 17(1), 13-19. https://doi.org/10.1016/j.tics.2012.11.004

Stoyle, K., \& Morris, B. (2017). Blogging mathematics: Using technology to support mathematical explanations for learning fractions. Computers \& Education, 111, 114127. https://doi.org/10.1016/j.compedu.2017.04.007

Trivena, V., Ningsih, A., \& Jupri, A. (2017). Misconception on addition and subtraction of fraction at primary school students in fifth-grade. Journal of Physics: Conf. Series, 895, 1-7. https://doi.org/10.1088/1742-6596/895/1/012139

Wang, S., \& Hsu, H. (2009). Using the ADDIE model to design second life activities for online learners. Tech Trends, 53(6), 76-82. https://doi.org/10.1007/s11528-0090347-x

Yilmaz, F., Özdemi, B., \& Yasar, Z. (2018). Using digital stories to reduce misconceptions and mistakes about fractions: an action study. International Journal of Mathematical Education in Science and Technology, 49(6), 867-898. https://doi.org/10.1080/0020739X.2017.1418919 